\title{
ARTICLE
}

\section{International spinal cord injury male sexual function and female sexual and reproductive function basic data sets-version 2.0}

\author{
Marcalee S Alexander ${ }^{1,2,3}$, Peter W New ${ }^{4,5,6}$, Fin Biering-Sørensen ${ }^{7}$, Frederique Courtois ${ }^{8}$, Giulio Del Popolo ${ }^{9}$, Stacy $^{\text {Elliott }}{ }^{10}$, \\ Carlotte Kiekens $^{11}$, Lawrence Vogel ${ }^{12,13}$ and Jean G Previnaire ${ }^{14}$
}

STUDY DESIGN: Data set review and modification.

OBJECTIVE: To describe modifications in the International Spinal Cord Injury (SCI) Male Sexual Function Basic Data Set Version 2.0 and the International SCI Female Sexual and Reproductive Function Basic Data Set Version 2.0.

SETTING: International expert work group using on line communication.

METHODS: An international team of experts was compiled to review and revise the International SCI Male Sexual Function and Female Sexual and Reproductive Function Basic Data Sets Version 1.0. The group adapted Version 1.0 based upon review of published research, suggestions from concerned individuals and on line work group consensus. The revised data sets were then posted on the International Spinal Cord Society (ISCOS) and American Spinal Injury Association (ASIA) websites for 2 months for review. Subsequently, the data sets were approved by the ISCOS Scientific and Executive Committees and ASIA board of directors. RESULTS: The data sets were modified to a self-report format. They were reviewed for appropriateness for the pediatric age group and adapted to include a new variable to address the issue of sexual orientation. A clarification of the difference between the data sets and the autonomic standards was also developed.

CONCLUSION: Sexuality is a continuously evolving topic. Modifications were needed to address this topic in a comprehensive fashion. It is recommended that Version 2.0 of these data sets are used for ongoing documentation of sexual status in the medical record and for documentation of sexual concerns during on-going research.

Spinal Cord Series and Cases (2017) 3, 17050; doi:10.1038/scsandc.2017.50; published online 10 August 2017

\section{INTRODUCTION}

Sexuality is an important issue for persons with spinal cord injuries (SCls) and non-traumatic spinal cord dysfunction (SCD). ${ }^{1}$ However, persons with $\mathrm{SCl}$ or SCD are often dissatisfied about the education and the treatment they receive regarding sexual concerns, ${ }^{2}$ and this lack of care may lead to a decrease in patient's participation in sexual activity and sexual satisfaction. Thus, it is important for clinicians to take sexual concerns into account and address them as they work to engage in patientcentered care.

The International SCI Basic Data Sets for Male Sexual Function and Female Sexual and Reproductive Function were developed in $2011^{3,4}$ as part of the overall International Data Sets project. Their purpose was to help provide a standardized platform that clinicians could use in the medical record to follow patient's sexual concerns. They included separate documentation of the concepts of psychogenic and reflex sexual arousal in both males and females along with the need for separate documentation of the retention of orgasmic capacity in both sexes and of ejaculation in males. Another purpose of the data sets was so researchers could use a basic data set to describe sexual concerns, thus promoting comparison of study results.

Based upon recent analyses and data set updates ${ }^{5,6}$ it was determined that updates to the International SCI Basic Data Sets for Male Sexual Function and Female Sexual and Reproductive Function are necessary. Subsequent to the development of Version 1.0, a validation study was performed that identified the need for a self-report format. ${ }^{5}$ In addition, the need to acknowledge sexual orientation and the issues of children were raised. In light of these concerns, it was determined that a revision of the basic data sets was necessary. The purpose of this article is to describe the developments of the International $\mathrm{SCI}$ Male Sexual Function Basic Data Set Version 2.0 and the International SCI Female Sexual and Reproductive Function Basic Data Set Version 2.0 and detail their differences from Version 1.0.

These changes are presented based upon the changes to Version 1.0. The complete syllabi are available for use on the ISCoS website: http:///www.iscos.org.uk/international-sci-male-sex ual-function-data-set, http:///www.iscos.org.uk/international-scifemale-sexual-and-reproductive-function-data-set.

\footnotetext{
${ }^{1}$ Birmingham VA Medical Center, Birmingham, AL, USA; ${ }^{2}$ Department of Physical Medicine and Rehabilitation, University of Alabama at Birmingham School of Medicine, Birmingham, AL, USA; ${ }^{3}$ Department of Physical Medicine and Rehabilitation Harvard School of Medicine, Boston, MA, USA; ${ }^{4}$ Spinal Rehabilitation Service, Caulfield Hospital, Alfred Health, VIC, Australia; ${ }^{5}$ Epworth-Monash Rehabilitation Medicine Unit, Southern Medical School, Monash University, Melbourne, VIC, Australia; ${ }^{6}$ Department of Epidemiology and Preventive Medicine, School of Public Health and Preventive Medicine, Monash University, Melbourne, VIC, Australia; ${ }^{7}$ Clinic of Spinal Cord Injuries, Neuroscience Centre, Rigshospitalet, University of Copenhagen, Copenhagen, Denmark; ${ }^{8}$ Department of Sexology, Université du Québec à Montréal, Montréal, Canada; ${ }^{9}$ Spinal Unit and Neuro-Urology, Careggi University Hospital, Florence, Italy; ${ }^{10}$ Department of Psychiatry and Urologic Sciences and ICORD, University of British Columbia, Vancouver, BC, Canada; ${ }^{11}$ Department of Physical and Rehabilitation Medicine, University Hospitals Leuven, Leuven, Belgium; ${ }^{12}$ Department of Pediatrics, Rush University Chicago, Chicago, IL, USA; ${ }^{13}$ Shriners Hospital for Children, Chicago, IL, USA and ${ }^{14}$ Spinal Unit, Centre Calve, Fondation Hopale, Berck-sur-Mer, France.
} 


\section{METHODS}

An international working group was formed, consisting of nine experts that included a urologist, family practitioner, pediatrician, sexual health researcher and five physiatrists, all with clinical expertise with sexuality issues in people who have $\mathrm{SCl}$ and with multiple publications in the field of sexuality and $\mathrm{SCl}$. There were no consumers involved in the process; however, it was felt that all participating experts were sufficiently knowledgeable about consumer concerns with regards to the topic. The group interacted on-line and assessed and discussed the original data sets and recommended changes. The literature was reviewed for relevant articles and publications subsequent to the initial publication of the data sets and disseminated to committee members. Based upon these discussions, changes were made to the data sets and consensus regarding these changes was achieved amongst committee members.

The adapted data sets were then sent for review by the International $\mathrm{SCl}$ Data Sets Committee. After approval they were sent to the International Spinal Cord Society (ISCoS) scientific and executive committees and the American Spinal Injury Association (ASIA) board of directors. Afterwards they were placed on ISCoS and ASIA websites for 2 months. Moreover, they were circulated to approximately 40 international societies and other interested persons for review. Subsequently, they were circulated to the ISCOS executive and scientific committees and the ASIA board of directors for final approval. During this process, as appropriate, further modifications were made to the data sets and participants acknowledged.

\section{RESULTS}

Appendix A and Appendix B present the data sets. Only one article was found which specifically addressed validation of these data sets. ${ }^{5}$ Subsequent review of the data sets revealed there could be some confusion with the original format as clinicians could interpret and ask patients about the questions in different ways and as a result obtain different data. Based upon this discussion the questions were changed to a self-report format.

Further discussion amongst the working group raised the concern regarding potential confusion between the sexuality data sets and the International Standards to Document Remaining Autonomic Function after $\mathrm{SCl}^{6}{ }^{6}$ Therefore, the sexuality data sets have also been modified to include reference and clarification of the use of the data sets versus the Autonomic Standards. These sexuality data sets are intended as tools to record data in the medical record or to use during research whereas the autonomic standards are designed as a tool to describe the neurologic impact of the $\mathrm{SCl}$ on autonomic responses.

The work group determined that sexual orientation and gender were significant omissions to the data sets. Therefore, the variable 'sexual orientation' has been added to the data sets along with appropriate values including 'heterosexual', 'bisexual', 'homosexual (gay or lesbian)', 'asexual', 'prefer not to say', and 'do not know'. It was noted that the determination had already been made that the issue of gender needed to be clarified in the International SCl Core Data Set $2.0^{8}$ which now includes a response option for 'Transgender or other related' gender orientations.

A number of other questions were also adapted during this process for Version 2.0. The question 'Are you interested in discussing sexual issues?' was modified to include the clause 'and or answering questions about'. The related values were changed to 'Yes would like to discuss sexual issues and answer questions', 'Yes but only interest in answering questions', and 'No, will not do either'. This is believed to be a more accurate portrayal of the circumstances of typical discussions. In addition, the variable 'sexual issues unrelated to the spinal cord lesion' was expanded to also include the details 'sexual problems or issues that were present before your spinal cord lesion or that occurred after your injury but are unrelated to the spinal cord lesion.' With the transition to a list of specific self-report questions for the patients this verbiage was deemed more appropriate. Furthermore, in multiple variables the option of 'not applicable' and 'unknown' was added.
In subsequent discussions with the International SCI Data Sets Committee, the issue was raised that these data sets needed to have a guidance given with regards to its appropriateness for the pediatric age group. The recommendations are that these data sets may be applicable for children as young as 12 but are generally applicable for children 15 years of age and above. It is vital that prior to the use of these data sets in children that the social, legal and religious circumstances are taken into account.

\section{DISCUSSION}

Six years after the original publications, this expert working group determined that Version 1.0 of the International SCI Male Sexual Function Basic Data Set ${ }^{3}$ and Version 1.0 of the International SCl Female Sexual and Reproductive Function Basic Data Set ${ }^{4}$ required revision. Based upon the work of New and Currie, ${ }^{5}$ the data sets were changed to a self-report format. This is different than most other data sets. Furthermore, the issue of sexual orientation and pediatric concerns were now deemed important components of data sets.

Unfortunately, the team only found one article specifically assessing use of these data sets. One reason for this may be that clinicians do not consistently evaluate patients' interest in sexual activity and their concerns and do not obtain detailed information about patients' sexual dysfunctions. This is unfortunate, because as more reports are published with regards to improving sexual responsiveness, ${ }^{9}$ it is important to have a standardized reporting system and in published research studies, there are often wide variations in the information provided to the readers. ${ }^{10}$ More importantly, it is useful to have a standard system to address and track improvement or decline in the sexual function of persons with $\mathrm{SCl}$ or SCD. Improvements need to be documented with addition of pro-sexual medications while negative side effects of other medications used to treat other organ system issues related to $\mathrm{SCl}$ should also be documented. While detailed listing of these other possible concerns are not addressed in the basic data sets, a future workgroup will be developing Extended Male and Female Sexual Function Data Sets in parallel with other workgroups that are developing Male Reproductive Function and Female Reproductive Function Extended Data Sets. In addition, it is planned that these workgroups will ensure consumer input into the data sets.

Based upon the review of current information and treatments regarding sexual concerns, we recommend clinicians work to make addressing the sexual health needs of persons with $\mathrm{SCls}$ a routine part of clinical care. Moreover, we strongly encourage the use of Version 2.0 of the International SCI Male Sexual Function Basic Data Set and International SCl Female Sexual and Reproductive Function Basic Data Set as part of the clinical treatment record and research endeavors.

\section{ACKNOWLEDGEMENTS}

The authors acknowledge Susie Charlifue and Thomas Kessler for their helpful comments regarding these data sets.

\section{COMPETING INTERESTS}

The authors declare no conflict of interest.

\section{PUBLISHER'S NOTE}

Springer Nature remains neutral with regard to jurisdictional claims in published maps and institutional affiliations. 


\section{REFERENCES}

1 Anderson KD. Targeting recovery: priorities of the spinal cord-injured population. J Neurotrauma 2004; 21: 1371-1383.

2 New PW, Seddon M, Redpath C, Currie KE, Warren N. Recommendations for spinal rehabilitation professionals regarding sexual education needs and preferences of people with spinal cord dysfunction: a mixed methods study. Spinal Cord 2016; 54: 1203-1209.

3 Alexander MS, Biering-Sorensen F, Elliott S, Kreuter M, Sonksen J. International spinal cord injury male sexual function basic data set. Spinal Cord 2011; 49: 795-798.

4 Alexander MS, Biering-Sorensen F, Elliott S, Kreuter M, Sonksen J. International spinal cord injury female sexual and reproductive function basic data set. Spinal Cord 2011; 49: 787-790.

5 New PW, Currie KE. Developoment of a comprehensive survey of sexuality issues including a relf-report version of the international spinal cord injury sexual function basic data sets. Spinal Cord 2016; 54: 584-591.
6 Alexander MS, Biering-Sorensen F, Bodner D, Brackett NL, Cardenas D, Charlifue S et al. International standards to document remaining autonomic function after spinal cord injury. Spinal Cord 2009; 47: 36-43.

7 Sell, RL. Defining and measuring sexual orientation for research. In: Meyer $\mathrm{IH}$ Northridge ME (eds). The Health of Sexual Minorities. Public Health Perspectives on Lesbian, Gay, Bisexual and Transgender Populations. Springer, 2007, pp 355-374.

8 Biering-Sørensen F, DeVivo MJ, Charlifue S, Chen Y, New PW, Noonan V et al. International Spinal Cord Injury Core Data Set (version 2.0)-including standardization of reporting. Spinal Cord (e-pub ahead of print 30 May 2017; doi:10.1038/sc.2017.59).

9 Alexander M, Courtois F, Elliot S, Tepper M. Improving sexual satisfaction in persons with sinal cord injuries: collective wisdom. Topics in Spinal Cord Injury Rehab 2017; 23: 57-70.

10 Alexander MS, Marson L. The neurologic control of arousal and orgasm with specific attention to spinal cord lesions: integrating preclinical and clinical sciences. Auton Neurosci (e-pub ahead of print 25 January 2017; doi:10.1016/j.autneu.2017.01.005). 
APPENDIX A

\section{International spinal cord injury female sexual and reproductive function basic data set (version 2.0) - data collection form}

Date of data collection: YYYYMMDD

Interest in discussing and answering questions about sexual issues

Yes

Yes, but only willing to answer questions for the medical record

No, unwilling to answer questions or discuss sexual issues

\section{Sexual orientation}

Heterosexual

Bisexual

Homosexual (lesbian)

Asexual

Prefer not to say

Do not know

Sexual problems prior or unrelated to the spinal cord lesion:

$\square$ No

$$
\text { Yes, specify }
$$
Unknown/Not applicable

Sexual dysfunction related to the spinal cord lesion:

$\square$ Yes $\square$ No

$\square$ Unknown/Not applicable

Psychogenic genital arousal

$\square$ Normal $\square$ Reduced/altered

$\square$ Absent $\quad \square$ Unknown/Not applicable

Reflex genital arousal

$\square$ Normal $\square$ Reduced/altered $\quad \square$ Absent $\square$ Unknown/Not applicable

Orgasmic function

$\square$ Normal $\quad \square$ Reduced/altered

$\square$ Absent $\quad \square$ Unknown/Not applicable

Menstruation

$\square$ Normal $\quad \square$ Reduced/altered

$\square$ Absent $\quad \square$ Not applicable $\square$ Unknown 


\section{APPENDIX B}

\section{International spinal cord injury male sexual function basic data set (version 2.0) - data collection form}

Date of data collection: YYYYMMDD

Interest in discussing and answering questions about sexual issues

Yes

Yes, but only willing to answer questions for the medical record

No, unwilling to answer questions or discuss sexual issues

\section{Sexual orientation}

Heterosexual

Bisexual

Homosexual (gay)

Asexual

Prefer not to say

Do not know

Sexual problems prior or unrelated to the spinal cord lesion:
$\square$ No
Yes, specify
Unknown/Not applicable

Sexual dysfunction related to the spinal cord lesion:
$\square$ Yes
$\square$ No
$\square$ Unknown/Not applicable

\section{Psychogenic Erection}

$\square$ Normal $\square$ Reduced/altered $\quad \square$ Absent $\square$ Unknown/Not applicable

\section{Reflex Erection}

$\square$ Normal $\square$ Reduced/altered $\quad \square$ Absent $\square$ Unknown/Not applicable

\section{Ejaculation}

$\square$ Normal $\square$ Reduced/altered $\quad \square$ Absent $\square$ Unknown/Not applicable

Orgasmic Function

$\square$ Normal $\quad \square$ Reduced/altered $\quad \square$ Absent $\square$ Unknown/Not applicable 